\title{
Ras inhibition boosts galectin-7 at the expense of galectin-1 to sensitize cells to apoptosis
}

\author{
Batya Barkan ${ }^{1}$, Adrienne D. Cox ${ }^{2}$, and Yoel Kloog ${ }^{1}$ \\ ${ }^{1}$ Department of Neurobiology, The George S. Wise Faculty of Life Sciences, Tel Aviv University, Tel Aviv, Israel \\ 2 Departments of Radiation Oncology and Pharmacology, Lineberger Comprehensive Cancer Center, University of North \\ Carolina at Chapel Hill, Chapel Hill, USA \\ Correspondence to: Yoel Kloog, email: kloog@post.tau.ac.il \\ Keywords: apoptosis, c-jun, farnesylthiosalicylic acid, FTS, galectin-1, galectin -7, JDP2, NF1, p53, Ras, Salirasib \\ Received: January 28, $2013 \quad$ Accepted: February 22, $2013 \quad$ Published: February 24, 2013
}

This is an open-access article distributed under the terms of the Creative Commons Attribution License, which permits unrestricted use, distribution, and reproduction in any medium, provided the original author and source are credited.

\section{ABSTRACT:}

Galectins are a family of $\beta$-galactoside-binding lectins that exert diverse extracellular and intracellular effects. Galectin-7 and galectin-1 show opposing effects on proliferation and survival in different cell types. Galectin-7 is a p53-induced gene and an enhancer of apoptosis, whereas galectin-1 induces tumorigenicity and resistance to apoptosis in several types of cancers. We show here that in cells derived from neurofibromin-deficient $\left(\mathrm{Nf1}^{-/-}\right)$malignant peripheral nerve sheath tumors (MPNSTs), Ras inhibition by S-trans,trans-farnesylthiosalicylic-acid (FTS; Salirasib) shifts the pattern of galectin expression. Whereas FTS decreased levels of both active Ras and galectin-1 expression, it dramatically increased both the mRNA and protein expression levels of galectin-7. Galectin-7 accumulation was mediated through JNK inhibition presumably resulting from the observed induction of p53, and was negatively regulated by the AP-1 inhibitor JDP2. Expression of galectin-7 by itself decreased Ras activation in ST88-14 cells and rendered them sensitive to apoptosis. This observed shift in galectin expression pattern together with the accompanying shift from cell proliferation to apoptosis represents a novel pattern of Ras inhibition by FTS. This seems likely to be an important phenomenon in view of the fact that both enhanced cell proliferation and defects of apoptosis constitute major hallmarks of human cancers and play a central role in the resistance of MPNSTs to anti-cancer treatments. These findings suggest that FTS, alone or in combination with chemotherapy agents, may be worth developing as a possible treatment for MPNSTs.

\section{INTRODUCTION}

The Ras superfamily control many cellular functions including cell growth, differentiation, motility and survival [1-6] and play a major role in cell transformation. They alternate between a GDP-bound (inactive) and a GTP-bound (active) state through the action of guanine nucleotide exchange factors (RasGEFs) and GTPase activating proteins (RasGAPS). Active Ras was found to interact specifically with two members of the galectins family; galectin-1 and galectin-3. [7-9].

Galectins are a phylogenetically conserved family of lectins that share consensus amino-acid sequences and the carbohydrate recognition domain responsible for $\beta$-galactoside binding [10]. They are located within the cells (cytoplasm and nucleus) and are also secreted into the extracellular space. Although originally considered only as extracellular structural elements, a large body of evidence testifying to their role in intracellular signaling has accumulated over the last decade. Galectins have been implicated in several cellular processes, including apoptosis, cell survival, cell adhesion, immune response, and gene expression (reviewed in [11] and [12]).

Overexpression of galectin-1, a prototype member of this family, has been documented in many different tumor types [13-15], and in various aspects of tumor biology including migration and invasiveness, chemoresistance [16], angiogenesis [17], immune escape [18] and malignant progression [19-21]. Galectin-1 interacts with the small GTPases H-Ras-GTP in the plasma membrane, 
resulting in stabilization of H-Ras-GTP, clustering of H-Ras-GTP and galectin-1 in non-raft microdomains [22], subsequent binding to Raf-1 (but not to PI3K or Ral-GEF $[7,23])$, activation of the ERK signaling pathway, and increased cell transformation [7].

As opposed to galectin-1, galectin-7-another member of the galectin superfamily-displays proapoptotic activity in various types of cells. Expression of galectin-7 is induced in the early steps of p53-mediated apoptosis and has been designated as the product of the p53-induced gene 1 (PIG1) [24]. A major function of p53 is control of apoptosis homeostasis [25], and it is the most frequently mutated gene in human tumors [25]. As opposed to galectin-7, galectin-1 is downregulated by p53 in glioma cells [26]. In line with its pro-apoptotic activity, galectin-7 inhibits DLD-1 cell proliferation in vitro and in vivo $[27,28]$ and is downregulated in transformed keratinocytes [29]. UVB irradiation induces apoptosis and galectin-7 expression in dependence with p53 [30, 31]. Ectopic expression of galectin-7 in HeLa and DLD-1 cells renders them more sensitive to a variety of apoptotic triggers, causes enhanced caspase-3 activity and poly(ADP-ribose) polymerase cleavage, and accelerated mitochondrial cytochrome-C release [32]. In addition, galectin-7 was found to bind directly to Bcl-2 in the mitochondria and to sensitize the mitochondria to apoptotic signals [33].

While galectin-7 negatively regulates some tumor types, it can stimulate the growth and/or development of others [34-37]. It thus seems that galectin-7 can act either as a positive or as a negative regulatory factor in tumor development, depending on the histological type of the tumor. Although the effect of p53 on galectin-7 expression is well established, little is known about how its transcription is regulated.

Although, as mentioned above, changes in expression levels of galectins have been implicated in many types of diseases including cancer, the role of galectins in neurofibromatosis type 1 (NF1) is still unknown. NF1 has an autosomal dominant mode of inheritance with a prevalence of about 1 in 3000 live births. It harbors a variety of phenotypes. The hallmark of NF1 is the neurofibroma, a benign peripheral nerve tumor comprised of transformed Schwann cells [38]. Neurofibromas undergo transformation into aggressive and chemotherapy-resistant malignant peripheral nerve sheath tumors (MPNSTs), which are prone to life-threatening metastasis [39].

Loss of neurofibromin Ras-GAP activity is associated with increased Ras-GTP and overactivation of Ras effectors [40], and reviewed in [41], leading to NF1 $[42,43]$. The role of Ras in NF1-based malignancy suggests that Ras inhibitors such as S-trans, transfarnesylthiosalicylic acid (FTS; Salirasib), which interfere with Ras-membrane anchorage [3], are likely to have useful therapeutic activity. Importantly, FTS interferes, both in vitro and in vivo, with the transformed phenotype of NF1-associated MPNST cell lines [44]. We recently discovered that FTS reverses the epithelialmesenchymal (EMT)-like transition phenotype of NF1deficient MPNST cells by perturbing the signaling of bone morphogenetic protein (BMP) 4 and transforming growth factor (TGF)- $\beta 1$ to SMAD-dependent and ERK-dependent pathways, inhibiting motility, spreading and gelatinase secretion, and alternating gene expression [45].

The activator protein-1(AP)-1 transcription-factor complex, which participates actively in cell proliferation, differentiation and cell transformation, is composed of homodimeric and heterodimeric complexes consisting of members of the Jun: Fos and Jun dimerization protein 2 (JDP2), activating transcription factors (ATFs) and other proteins [46]. c-jun, which is phosphorylated by c-Jun terminal kinase (JNK) through Ras-induced signaling [47-49], cooperates with Ras in cell transformation [50, 51] and has been shown to interfere with p53-induced apoptosis [52, 53]. JDP2 heterodimerizes with c-jun [54], and functions as a repressor of the AP-1 protein family by interfering with the c-jun-induced transformation [55]. JDP2 inhibits cell proliferation [56] and cell transformation, both induced by Ras [57]. Thus, on the one hand JDP2 inhibits cell transformation induced by Ras; on the other hand, it has been identified as a candidate oncogene in mouse hepatocellular carcinoma [58] and in a high-throughput screen in mice [59-61].

Here we show that Ras inhibition in NF1-deficient MPNST cells dramatically increases galectin-7 expression and decreases the expression of galectin-1. The increase in galectin-7 was dependent on JNK inhibition. We found that expression of galectin-7 itself modulates Ras signaling and renders MPNST cells more sensitive to apoptosis, suggesting the possible existence of cross-talk between Ras and galectin- 7 .

\section{RESULTS}

\section{Ras inhibition induces galectin-7 and reduces galectin-1 expression in NF1-deficient MPNST cells}

Ras inhibition by FTS in NF1-deficient MPNST cells inhibits their transformed phenotype both in vitro and in vivo [44], reverses their EMT-like phenotype, and alters gene expression [45]. One of the most significantly upregulated genes in our microarray analysis was the $\beta$-galactosidase-binding lectin, galectin-7, with an increase of 22.6-fold in its transcript in ST88-14 cells after FTS treatment. Galectin-7 is considered to be an apoptotic regulator, whose mRNA is highly induced by p53 [24] and whose expression sensitizes HeLa and DLD-1 cells to apoptosis through enhanced caspase-3 activity [32]. 
A.
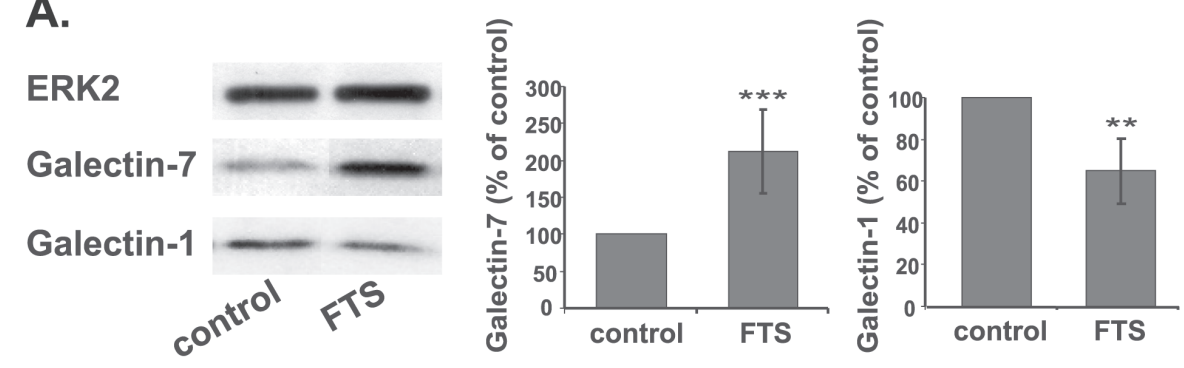

B.
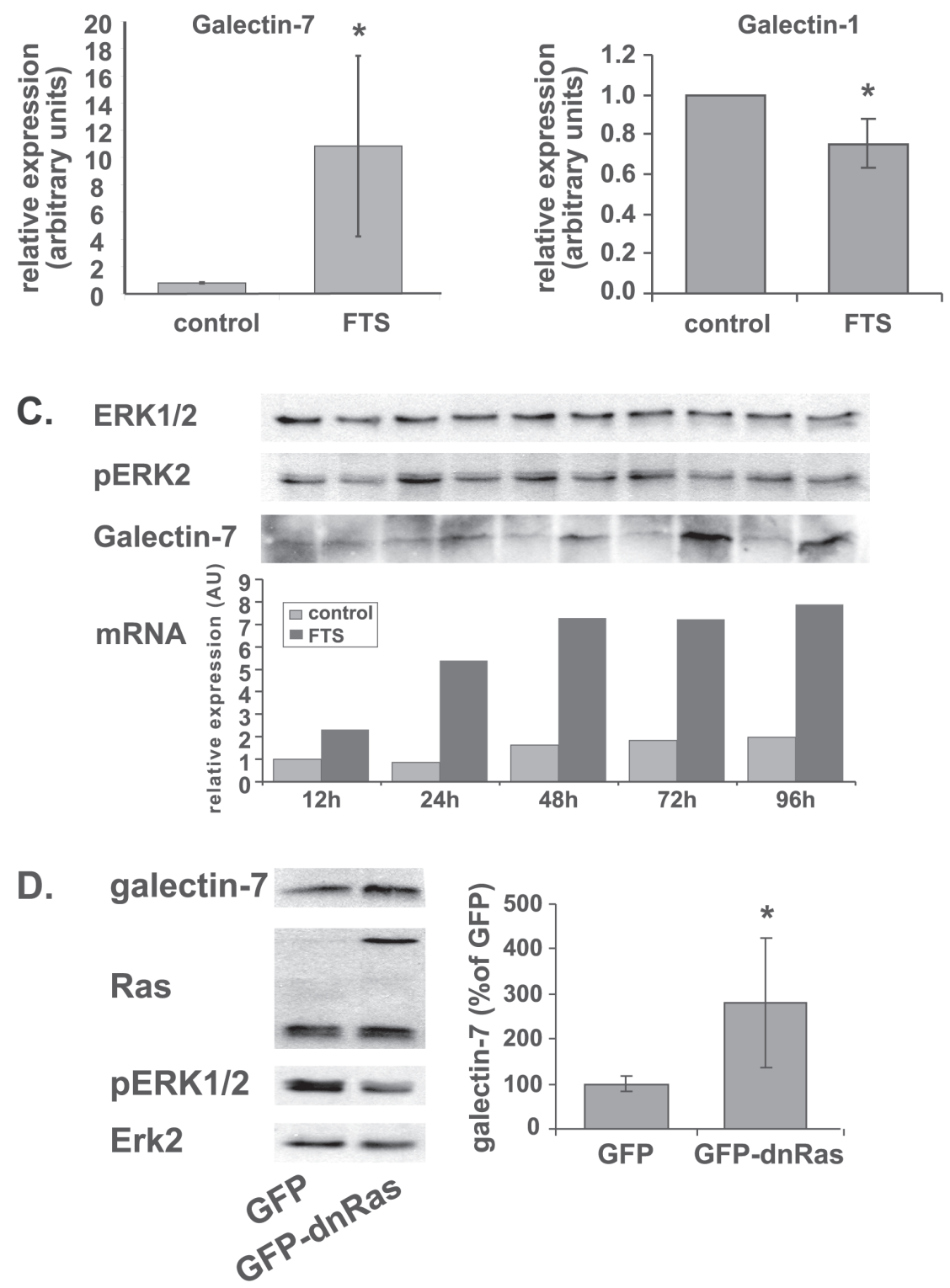

Figure 1: FTS induces a shift in galectin-1 and galectin-7 expression levels. (A) ST88-14 cells were treated for $48 \mathrm{~h}$ with FTS $(75 \mu \mathrm{M}, 5 \%$ FCS $)$ or vehicle followed by immunoblotting with galectin-7 or galectin-1 antibodies. ERK2 served as loading control. Immunoblots from a typical experiment are shown in the left panel. Graphs depict quantification of galectin-1 (right) and galectin-7 (center) $(* * \mathrm{p}<0.01, * * * \mathrm{p}<0.001, \mathrm{n}=6)$. (B) Relative expression of galectin-7 and galectin- $1 \mathrm{mRNA}$ were detected by real-time PCR $(* \mathrm{p}<0.005, \mathrm{n}=4$ and $n=3$ respectively). (C) ST88-14 cells were treated with FTS $(75 \mu \mathrm{M}, 5 \%$ FCS $)$ for the indicated times and immunoblotted with antigalectin-7, anti pERK 1/2 or anti ERK2 antibodies or subjected to real-time PCR for assay of galectin-7 mRNA. A typical experiment is shown. (D) ST88-14 cells were transfected with GFP or GFP-H-Ras(17N) (dnRas) by nucleofection, as described in Methods. After $24 \mathrm{~h}$ cells were lysed and subjected to western blot analysis with the indicated antibodies. Typical blots are shown in the left panel; right panel depicts quantification of galectin-7 $(\mathrm{n}=3, * \mathrm{p}<0.05)$. ERK2 served as loading control. 
Treatment with FTS (75 $\mu \mathrm{M}, 48 \mathrm{~h}, 5 \%$ serum) markedly increased the amounts of galectin-7 protein in the NF1-deficient MPNST cell lines ST88-14 (Figure $1 \mathrm{~A}, 211 \%$ of control, $\mathrm{p}<0.001, \mathrm{n}=6$ ) and $\mathrm{T} 265 \mathrm{p} 21$ (supplementary Figure 1A). No such increase was seen after FTS treatment of the non-NF1 STS26T cell line or of the NF1-deficient cell line 90-8 (Supplementary Figure 1A). It is worth noting that both of the cell lines in which Ras inhibition induced an increase in galectin-7 (i.e., ST88-14 and T265P21) harbor wild-type p53, whereas the two cell lines in which galectin-7 was unaffected by FTS harbor mutated p53 [66]. FTS treatment of ST8814 cells also increased their galectin-7 mRNA content, as detected by real-time PCR (Figure 1B, 1040\% of control, $\mathrm{p}<0.05, \mathrm{n}=4$ ). In contrast to galectin-7 mRNA, our microarray analysis indicated that galectin- 1 mRNA was downregulated by 14 fold following FTS treatment, a trend that was validated by real-time PCR analysis (Figure 1B, $76 \%$ of control, $\mathrm{p}<0.05, \mathrm{n}=4)$ and was accompanied by a decrease in galectin-1 protein in ST88-14 cells (Figure 1A, $64 \%$ of control, $\mathrm{p}<0.01, \mathrm{n}=4)$. These results are consistent with earlier reports of galectin-1 downregulation by inhibition of Ras $[7,8]$.

To follow the dynamics of the FTS-induced increase in galectin-7 mRNA and protein, we treated ST88-14 cells with FTS $(75 \mu \mathrm{M}, 5 \% \mathrm{FCS})$, and monitored the change over time by real-time PCR and Western blotting for different time periods From $12 \mathrm{~h}$ after FTS treatment galectin-7 mRNA increased in a time-dependent manner, reaching a plateau at $48 \mathrm{~h}$ after treatment. Galectin-7 protein levels started to increase at $24 \mathrm{~h}$ after treatment and reached a maximum at $72 \mathrm{~h}$ (Figure $1 \mathrm{C}$ ).
A.

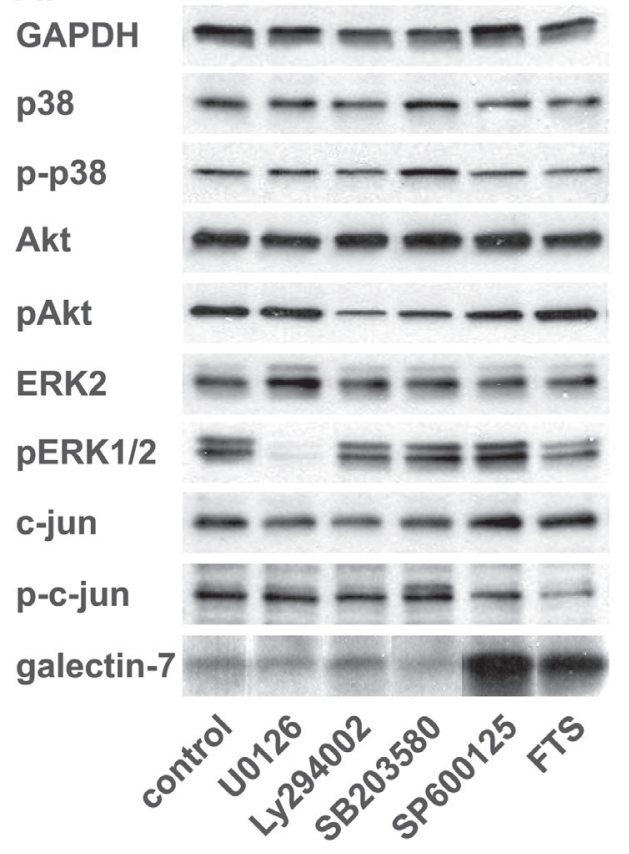

B.
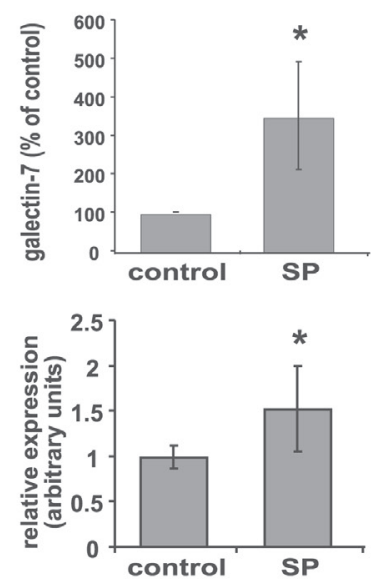

C.

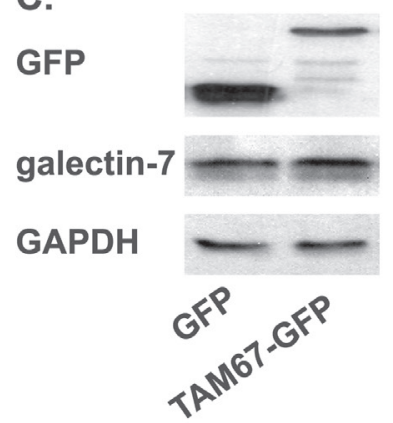

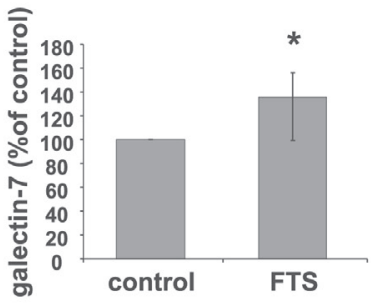

Figure 2: JNK inhibition increases galectin-7 protein and mRNA levels. (A) ST88-14 cells were treated for $48 \mathrm{~h}$ with U0126 (10 $\mu \mathrm{M})$, LY294002 (20 $\mu \mathrm{M})$, SB203580 (4 $\mu \mathrm{M})$, SP600125 (25 mM), FTS (75 $\mu \mathrm{M})$ or vehicle, followed by immunoblotting with the indicated antibodies. (B) Quantification of ST88-14 treated as in (A) and assayed for galectin-7 protein by western blotting (upper panel) or for mRNA by real-time PCR (lower panel). SP for SP600125 (C) ST88-14 cells were transfected with GFP or GFP-TMA67 by nucleofection, as described in Methods. After $24 \mathrm{~h}$, cells were lysed and subjected to western blot analysis with the indicated antibodies. Typical blots are shown in the left panel; right panel depicts quantification of galectin-7 protein expression $(n=3, * p<0.05)$. GAPDH served as loading control. 
To determine whether the FTS-induced upregulation in galectin-7 protein was a result of the Ras inhibition, we evaluated galectin-7 in ST88-14 and T265P21 cells transfected with GFP-H-Ras(17N) (dnRas) or, as a control, with GFP. Transfection of dnRas induced a significant increase in galectin-7 expression levels in both the ST88-14 (Figure 1D, 280\% of GFP, $\mathrm{p}<0.05, \mathrm{n}=4$ ) and the T265p21 cells (Supplementary Figure 1B, 122\% of GFP, $\mathrm{p}<0.06, \mathrm{n}=3$ ). As expected, the cells transfected with dnRas exhibited decreased ERK phosphorylation, indicating that the transfected vector was indeed reducing Ras activation (Figure 1D). This strengthens the notion that the FTS-induced increase in galectin-7 is a result of Ras inhibition.

The protein synthesis inhibitor cycloheximide completely inhibited the FTS-induced increase in galectin-7 (Supplementary Figure 1C), further supporting the notion that regulation of the transcription was mediated by Ras.
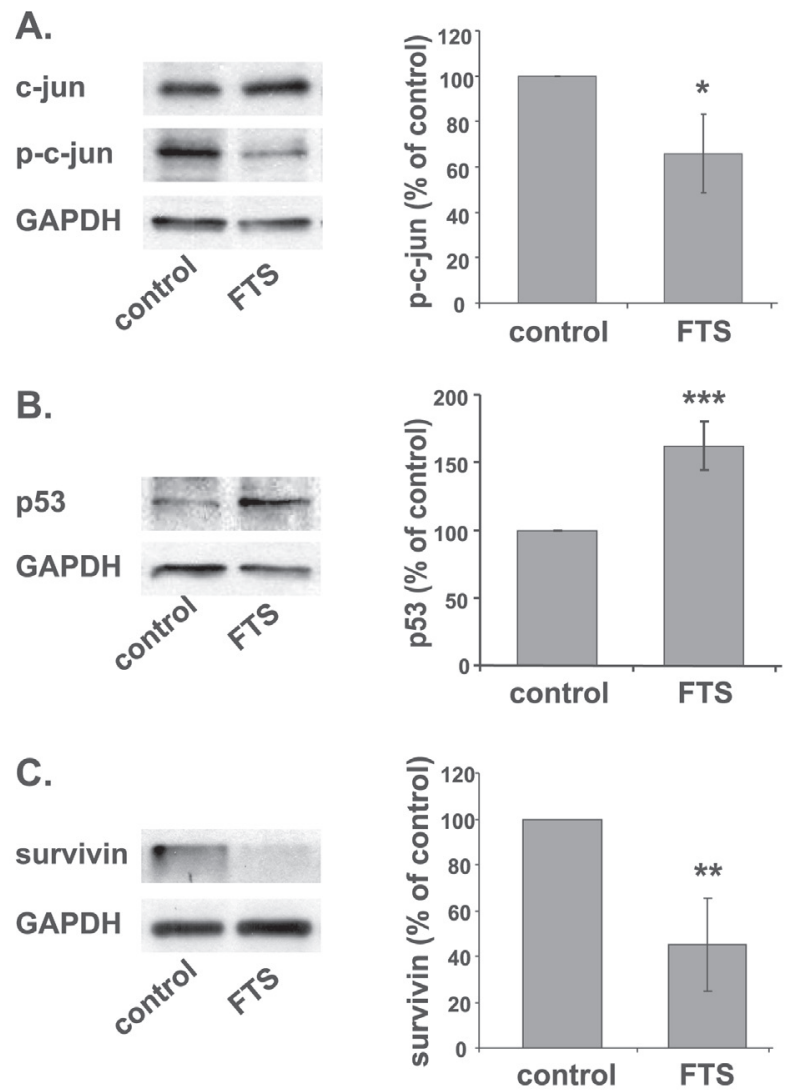

Figure 3: Ras inhibition induces galectin-7 transcription through p53 and c-jun. (A, B) ST8814 cells were treated for $48 \mathrm{~h}$ with FTS $(75 \mu \mathrm{M}, 5 \%$ FCS $)$ or vehicle followed by immunoblotting with anti- p-c-jun and total c-jun (A) or anti-p53 (B) antibodies. GAPDH served as loading control. Immunoblots from a typical experiments are shown in the left panels; graphs depicting quantification\{?depicting assay of p-c-jun (A) or p53 (B) are shown in the right panel (A; $* \mathrm{p}<0.05, \mathrm{n}=3, \mathrm{~B} ; * * * \mathrm{p}<0.001, \mathrm{n}=5)$.

\section{Galectin-7 expression is induced by JNK inhibition}

To find out which Ras-signaling pathway leads to the galectin-7 upregulation described above, we employed several chemical inhibitors of some of the most prominent Ras effectors: U0126, a MEK inhibitor; LY 294002, a PI3K inhibitor; SB203580, a p38 inhibitor, and SP600125, a JNK inhibitor. Western blot analysis showed that phosphorylation of all the relevant target proteins was curbed by their respective inhibitors (Figure 2A), with the exception of p38, on which SB203580 had no effect. Notably, in ST88-14 cells inhibition of the JNK pathway alone induced a pronounced increase in galectin-7 protein (Figure 2A, B), which was accompanied by an increase in galectin-7 mRNA (Figure 2B). Treatment of T265p21 cells with SP600125 also resulted in a robust increase in galectin-7, like that in ST88-14 cells (Supplementary Figure 2A).

By using a dominant-negative c-jun protein (TAM67), we further verified that inhibition of JNK and its phosphorylation target c-jun indeed induced galectin-7 protein. Transient transfection with TAM67 significantly increased galectin-7 expression in ST88-14 cells, strengthening the notion that c-jun is a major player in the Ras-induced increase in galectin-7.

\section{Ras inhibition induces galectin-7 transcription through p53, c-jun, and JDP2}

Following the notion that galectin-7 accumulates in response to inhibition of Ras or c-jun, we examined whether Ras inhibition in ST88-14 cells directly inhibits c-jun. A decrease in phospho-c-jun in these cells was indeed observed after treatment with FTS (Figure 3A, $67 \%$ of control, $* \mathrm{p}<0.05, \mathrm{n}=3$ ), suggesting that Ras inhibition induces galectin-7 expression by inhibiting c-jun activation.

Expression of galectin-7 is regulated by the tumor suppressor p53 [24], which is one of the most frequently mutated genes in cancer [25]. Analysis of the promoter region of galectin-7 gene using a Genomatix Genome Analyzer (Genomatix Software GmbH [65]) indeed revealed a putative p53-binding site (Supplementary Figure 2B). ST88-14 cells harbor wild-type p53, although its levels under normal growth conditions are small. We therefore followed changes in the amounts of $\mathrm{p} 53$ protein after FTS-induced inhibition of Ras in ST88-14 and T265P21 cells. In agreement with results obtained in the case of colon cancer [67], treatment with FTS resulted in a significant accumulation of p53 protein (ST88: Figure 3B, $163 \%$ of control, $* * * \mathrm{p}<0.001, \mathrm{n}=5$; T265P21: Supplementary Figure 2 C, $213 \%$ of control, $* * \mathrm{p}<0.01$, $\mathrm{n}=3$ ).

Upregulation of p53 in ST88-14 cells was also found 
here to lead to a significant decrease in the anti-apoptotic protein survivin (Fig 3C, 45\% of control, $\mathrm{p}<0.01$, $\mathrm{n}=5$ ) and in its mRNA (Figure 3C, $8 \%$ of control, $\mathrm{p}<0.001, \mathrm{n}=4$ ). This was an interesting finding, in view of a report that transcription of survivin is repressed by wild-type p53 $[68,69]$. Our finding is also in line with the previously described decrease in survivin by FTS in U87 [70] and DLD1 cells [71].

Given our observations that JNK inhibition induced a dramatic increase in galectin-7 and that FTS itself inhibits c-jun phosphorylation, we searched for c-jun regulatory elements in the galectin-7 promoter. Using Genomatix, we found putative binding sites for AP-1 and for the AP-1 inhibitor JDP2 (Supplementary Figure 2B). Because JDP2 participates in the p53 signaling pathway [72] and is regulated by c-jun [73], we investigated its possible involvement in the regulation of galectin-7 transcription. First, we analyzed changes in the amounts of JDP2 mRNA after FTS treatment. Figure 4A shows that JDP2 transcripts were increased by 2.5 -fold in FTS-treated cells compared to control $(* * \mathrm{p}<0.01, \mathrm{n}=6)$. Inhibition of JNK by SP600125 also increased JDP2 mRNA (Figure 4B, 1.7-fold compared to control, ** $\mathrm{p}<0.01, \mathrm{n}=3$ ). Other studies demonstrated the phosphorylation of JDP2 on Thr148 by JNK leading the protein to proteasomal degradation [73], supporting the negative role of JNK on JDP2 levels.
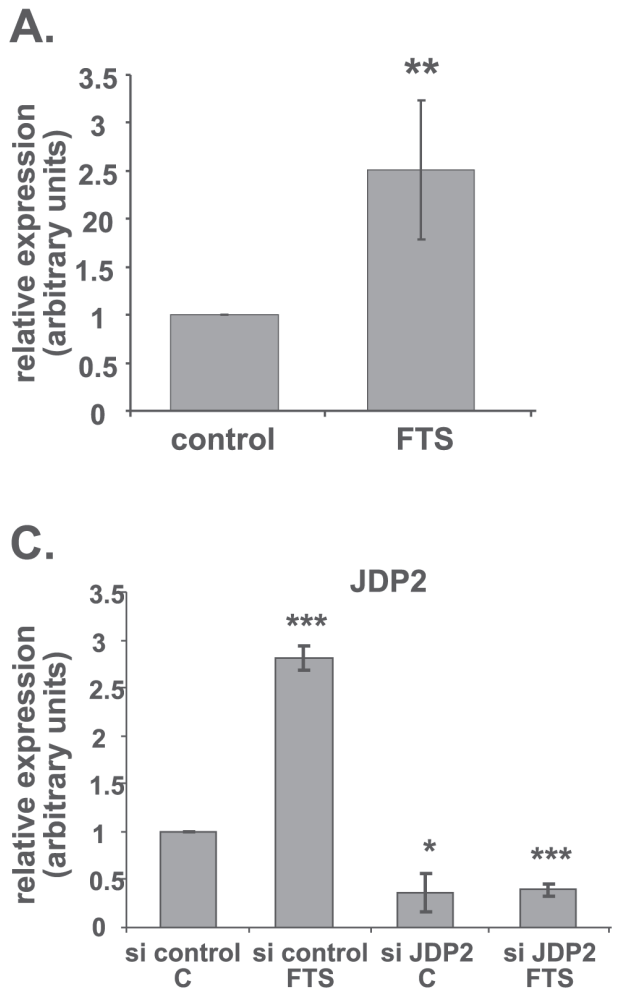

Next, we examined effect of using a specific small interfering RNA (siRNA) to decrease JDP2 expression. Figure 4C shows that transfection of cells with a specific siRNA against JDP2 reduced JDP expression to 0.36 fold of that obtained with a nonspecific siRNA $(* \mathrm{p}<0.05$, $\mathrm{n}=3$ ). In the latter transfected cells, the FTS-induced increase in JDP2 was maintained (Figure 4C, 2.8-fold of control; *** $<<0.001, \mathrm{n}=3$ ), exactly as shown in Figure 1A. However, JDP2-siRNA markedly decreased the FTS-induced JDP2 accumulation to 0.14 -fold of that in the non-target-siRNA transfected cells treated with FTS. Surprisingly, after the former transfection, induction of galectin-7 mRNA in the FTS-treated cells showed a dramatic 83.3-fold increase compared to an increase of only 5.2-fold in the control FTS-treated cells transfected with non-target siRNA (Figure 4D). Accumulation of galectin-7 mRNA was also significantly increased without FTS treatment: in cells transfected with siRNA for JDP2 and treated with vehicle, galectin-7 mRNA was 1.46-fold higher than in the nonspecific siRNA transfectants (Figure $4 \mathrm{D}, * * \mathrm{p}<0.01, \mathrm{n}=3)$.

\section{Galectin-7 expression inhibits Ras and sensitizes ST88-14 cells to apoptosis}

We have previously shown that galectin-1 expression stabilizes Ras in its GTP-binding state and

B.

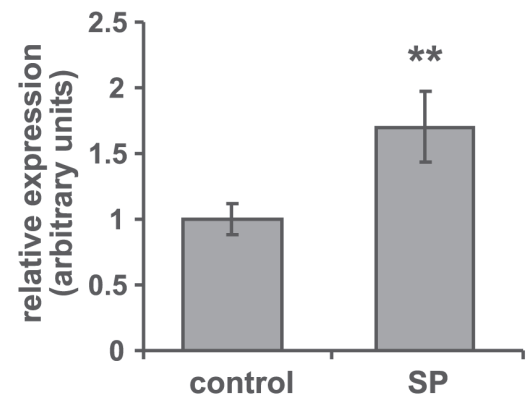

D.

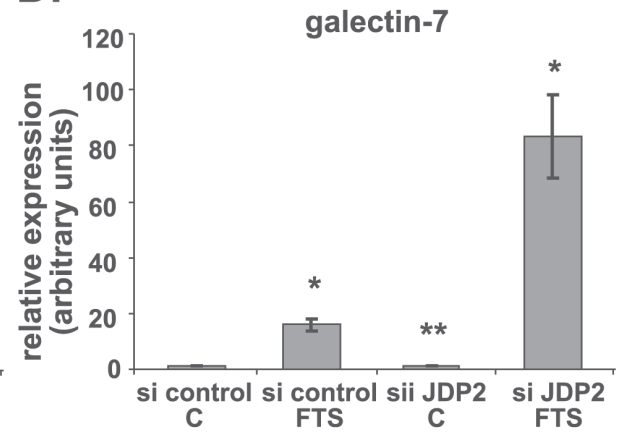

Figure 4: JDP2 inhibition boosts galectin-7 transcription. (A, B) ST88-14 cells were treated for 48 h in 5\% FCS with FTS (A; $75 \mu \mathrm{M})$ or with SP600125 (B; $25 \mathrm{mM})$. JDP2 mRNA was assayed by real-time PCR (**p $<0.01 ;(\mathrm{A}), \mathrm{n}=6$; (B), n=3). (C, D) ST88-14 cells transfected with non-targeting siRNA (si control) or with siRNA against JDP2 (si JDP2) were treated, $24 \mathrm{~h}$ after transfection, with FTS $(75 \mu \mathrm{M}, 5 \%$ FCS $)$ or vehicle. JDP2 (C) and galectin-7 (D) mRNA were assayed by real-time PCR $(* \mathrm{p}<0.05, * * \mathrm{p}<0.01, * * * \mathrm{p}<0.001, \mathrm{n}=3)$. 
that antisense galectin-1 reduces Ras activation [7]. Having detected an increase in galectin-7 and a decrease in galectin-1 in ST88-14 cells after Ras inhibition, we wanted to find out whether expression of galectin-7 affects Ras activation. To that end, ST88-14 cells were infected with viruses containing galectin-7 DNA (ST88/ gal7) or, as a control, GFP (ST88/GFP). After selection and validation of expression, the amounts of Ras-GTP in the ST88/gal7 cells were compared to those in ST88/ GFP and in noninfected ST88-14 cells. Notably, stable expression of galectin-7 in ST88-14 cells resulted in a

A.
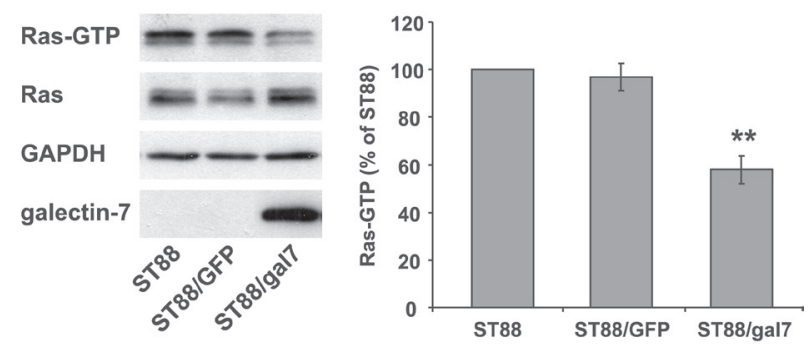

B.
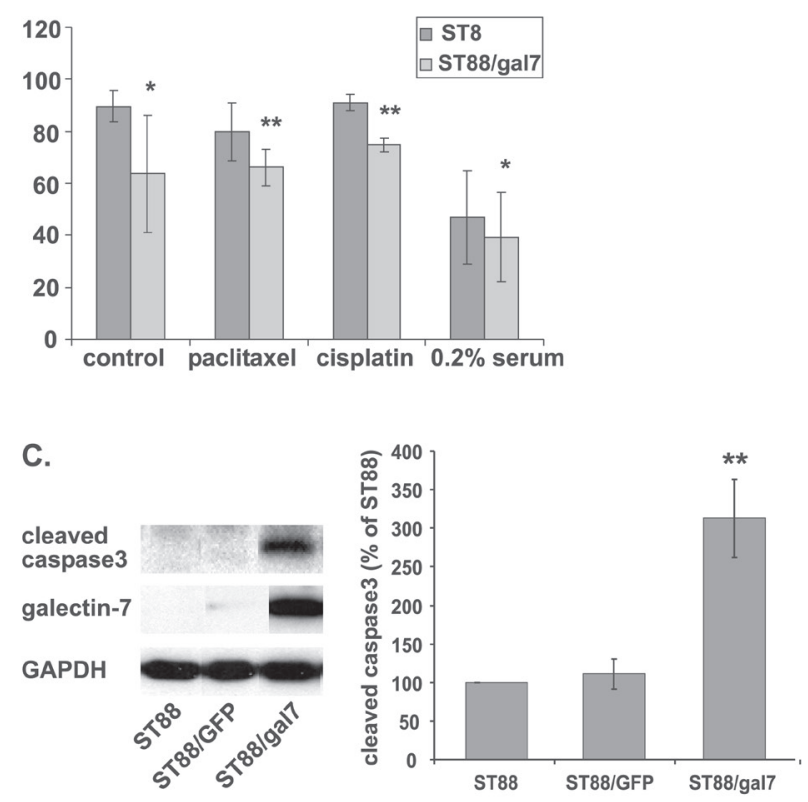

Figure 5: Galectin-7 expression inhibits Ras and sensitizes ST88-14 cells to apoptosis. (A) Wild-type ST88-14 cells (ST88) or ST88-14 cells stably infected with GFP (ST88/GFP) or galectin-7 (ST88/gal7) were subjected to Ras-GTP pull-down assay and immunoblotted with anti-Ras, anti-galectin-7, or anti-GAPDH antibodies. Left panel depicts a typical experiment; quantification (\% of control) is shown in the right panel (** $\mathrm{p}<0.01, \mathrm{n}=3$ ). (B) ST88 or ST88/gal7 cells were treated with paclitaxel $(10 \mathrm{nM})$, cisplatin $(1 \mu \mathrm{M})$, or vehicle in growth medium or under serum deprivation $(0.2 \% \mathrm{FCS})$ for 24 $\mathrm{h}$, then collected, stained with FITC-conjugated annexin V and PI, and analyzed by flow cytometry $(* \mathrm{p}<0.05, * * \mathrm{p}<0.01, \mathrm{n}=3)$. (C) ST88, ST88/GFP or ST88/gal7 cells (5\% FCS, 48 h) were lysed and immunoblotted using cleaved caspase 3, galectin-7 or GAPDH antibodies. Typical immunoblots are shown in the left panel and quantification of cleaved caspase 3 ( $\%$ of control; $* * \mathrm{p}<0.01, \mathrm{n}=4)$ in the right panel. marked reduction of Ras activity to $58 \%$ of that in GFPinfected or noninfected cells (Figure $5 \mathrm{~A}, * * \mathrm{p}<0.01, \mathrm{n}=3$ ). We could not detect any significant changes in $p E R K$, p-Akt or p-c-jun levels (data not shown).

That galectin-7 expression sensitizes cells to caspase-mediated apoptosis induced by several agents has by now been well established [32]. Unpublished data from our lab has demonstrated that treatment of ST8814 cells with FTS together with several chemotherapy agents. i.e., paclitaxel, doxorubicin, or cisplatin induces a synergistic effect on cell proliferation and enhances cell death. We therefore examined whether the FTS-induced accumulation of galectin-7 might render NF1-deficient cells more sensitive to apoptosis. ST88-14 and ST88/ gal 7 cells were treated with different cell-death inducers (paclitaxel, cisplatin, or serum deprivation $(0.2 \%$ FCS $)$ ) and assayed for cell viability using annexin-V/PI staining followed by FACS analysis. As shown in Figure 5B, expression of galectin-7 reduced the percentage of live (nonapoptotic) cells as indicated by negative staining for both PI and annexin-V. Those results indicate that galectin-7 expression sensitizes ST88-14 cells to apoptotic triggers, in agreement with the report by Kuwabara et al. [32].

Next, we examined the nature of galectin-7-induced susceptibility to apoptosis. Galectin-7 expression has been shown to cause enhanced caspase-3 activity [14, 32 ] and to sensitize urothelial cancers to cisplatin [28]. In agreement with these findings we detected high levels of cleaved caspase-3 in ST88/gal7 cells, whereas in control

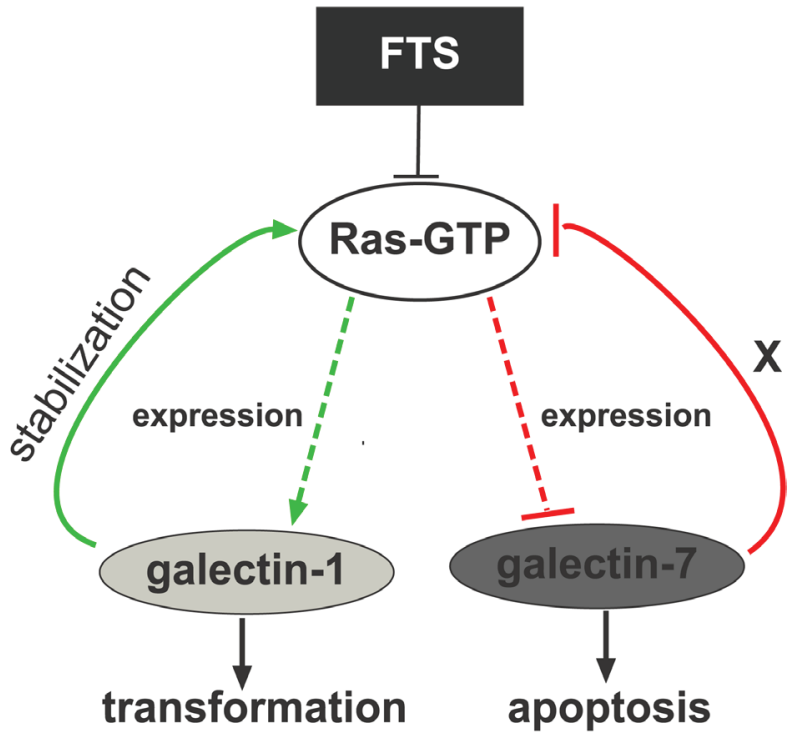

Figure 6: Model depicting the galectin-1/galectin-7 switch. High Ras-GTP increases galectin-1 expression and inhibits galectin-7 expression through JNK. Galectin-1 itself stabilizes and increases Ras-GTP, thereby inducing transformation. Inhibition of Ras by FTS or dnRas reduces galectin-1 expression and induces robust expression of galectin-7. High levels of galectin-7 inhibit Ras activation and sensitize cells to apoptosis. 
cell lines the cleaved form of caspase- 3 was undetectable (Figure $5 \mathrm{C}, * *_{\mathrm{p}}<0.01, \mathrm{n}=4$ ).

\section{DISCUSSION}

We show here that in the NF1-deficient ST8814 and T265P21 MPNST cell lines, Ras inhibition by FTS or dnRas dramatically induced expression of the pro-apoptotic protein galectin-7 (Figure 1 for ST88-14, Supplementary Figure 1B for T265P21). This was evident (for ST88-14) from the microarray analysis (22.6-fold increase), RT-PCR (1040\% of control), and western blotting (211\% of control). In contrast, FTS treatment reduced the expression of galectin-1, as also shown by microarray analysis, real-time PCR, and western blot analysis (Figure 1A, B). The negative regulation of Ras on galectin-7 expression is probably mediated through the consequent activation of the $\mathrm{JNK}-\mathrm{c}$-jun pathway, because the inhibition of JNK by SP600125 or dn-c-jun, but not inhibitors of other Ras signaling pathways, reproduced the FTS-induced increase in galectin-7 protein seen in ST8814 and T265P21 cells (Figure 2A-C and Supplementary Figure 2A). Moreover, FTS treatment itself inhibited c-jun phosphorylation (Figure 3A).

Bioinformatics analysis of galectin-7 upstream elements revealed predicted AP-1/c-jun and p53 regulatory elements. The role of p53 in galectin-7 induction has been well established [24, 26, 30] [31]. In conformity with this, the FTS-induced increase in galectin-7 was accompanied by an increase in the amounts of p53 protein (Figure 3B). Because galectin-7 was found to increase after Ras inhibition, it is reasonable to suggest that the regulation of this increase might be mediated by a c-jun-related repressor such as JDP2. This protein binds members of the AP-1 family such as c-jun, ATF-3, and ATF-2, preventing them from exerting their transcription activity [74]. The galectin-7 promoter also contains a potential JDP2-binding element. Accordingly, inhibition of JDP expression by siRNA transfection resulted in a dramatic increase in galectin-7 mRNA after FTS treatment (a 5.2fold increase compared to FTS-treated control siRNAtransfected cells, and an increase of 83-fold compared to vehicle-treated control si-RNA transfected cells (Figure 4C, D). Unexpectedly, we also detected an unexplained increase in JDP2 mRNA after inhibition of Ras or JNK (Figure 4A, B).

Galectin-7 expression has been shown to sensitize cells to apoptosis and enhance cleavage of caspase-3 [32, 33]. Importantly, stable expression of galectin-7 in ST8814 cells rendered them more sensitive to apoptotic signals and induced caspase- 3 cleavage under normal growth conditions (Figure 5B, C). Interestingly, active Ras in ST88-14 cells stably expressing galectin-7 was reduced in comparison to that in naîve or GFP-expressing cells (Figure 5A).

Studies have shown that expression of galectin-7 is induced as a result of cellular stress such as UV irradiation $[30,31]$ and is mediated by p53 [24, 75]. We report here, for the first time, that the expression of galectin-7 is negatively regulated by Ras-GTP. In the MPNSTs of NF1 patients, lack of functional neurofibromin leads to chronically active Ras. Inhibition of Ras in MPNST cells in the present study led to dramatic expression of galectin-7, mediated most probably through the FTSinduced decrease in p-c-jun levels, since inhibition of JNK or c-jun yielded similar induction of galectin-7. Notably, in two p53-mutated MPNST cell lines, STS26T and 90-8 [66], no increase in galectin-7 after Ras inhibition was detectable. It thus seems that p53 is a key factor in galectin-7 expression. Moreover, FTS-induced inhibition of Ras significantly increased p53 expression and the consequent reduction of survivin in the wild-type p53 cell lines. Induction of p53 after Ras inhibition has been reported in colon cancer [76] and in pancreatic cancer [67] cell lines. Inhibition of c-jun was shown to promote apoptosis, arguably through a p53-dependent mechanism, and to reduce liver cancer in mice [52].

We postulate that in NF1-deficient MPNST cells, high Ras activity results in low p53 levels together with intense c-jun phosphorylation. P-c-jun then heterodimerize with JDP2 to inhibit the galectin-7 promoter. Ras inhibition induced by FTS treatment increases p53 levels, thereby triggering p53-dependent galectin-7 transcription. The FTS-induced Ras inhibition also inhibits c-jun phosphorylation, thus dispersing the c-jun/ JDP2 heterodimer and allowing galectin-7 transcription. Indeed, decreasing JDP2 levels using specific siRNA might also disperse the dimer thereby freeing the gal7 promoter and making the cells more sensitive to FTSinduced galectin-7 accumulation. High galectin-7 levels in turn rendered MPNST cells more sensitive to apoptotic factors, promoted the apoptosis process and restrained Ras activity, thus sensitizing the cells to chemotherapy or radiotherapy. In addition, the secreted galectin-7 might be taken up by neighboring cells and affect their Ras signaling, as previously reported for galectin-1 [77]. Moreover, we were able to demonstrate a possible reciprocity in galectin-7/Ras relations, since galectin-7 itself reduced Ras activity. This is reminiscent of the effect of galectin-1 on stabilizing Ras in its GTP-binding state [7].

Galectin-1 promotes tumor growth [15, 19-21] and has been described as a cytokine-like factor that participates in the promotion of tumor angiogenesis [17]. Moreover, Ras can be dislodged from the plasma membrane by inhibition of galectin-1 employing antisense DNA [7], by application of the anti-angiogenic peptide anginex [77], or by disruption (via a point mutation (11A) [78]) of its ability to bind Ras. This results in a decrease in Ras-GTP and inhibition of the Raf-MEKERK cascade $[7,77,78]$. Previously we indeed observed that anginex significantly inhibits proliferation of NF1- 
deficient MPNST cells (unpublished data). Thus, Ras-GTP might cooperate with galectin-1 to induce tumorigenicity in NF1-deficient cells, while "shutting down" galectin-7 expression.

Altogether, these results point to a galectin-1/ galectin-7 switch, in which FTS-induced Ras inhibition reverses the expression pattern of MPNST galectins, as suggested in the model in Figure 6. Galectin-7 reportedly has some effects that oppose those of galectin-1: whereas galectin-1 promotes tumor growth [15, 19-21] and induces resistance to apoptosis, galectin-7 induces apoptosis in several types of cancer cells $[28,32]$. It is tempting to speculate on the presence of a mechanism of inhibitory cross-talk in which in several transformed cells, and particularly in NF1-deficient MPNSTs, high Ras activity stimulates galectin-1 and inhibits galectin-7 expression. Inhibition of Ras-GTP by FTS decreases galectin-1 expression, promoting inhibition of cell transformation while increasing galectin-7 expression with resulting heightened sensitivity to apoptosis.

\section{MATERIALS AND METHODS}

\section{Cell culture}

The human MPNST cell lines ST88-14, T265P21, 90-8 ( $\mathrm{NF}^{-/-)}$and the STS26T cell line $\left(\mathrm{NF}^{+/+}\right)$were a kind gift from Dr. Nancy Ratner (Cincinnati Children's Hospital and Medical Center, University of Cincinnati). All cell lines were routinely checked for mycoplasma, maintained, and subjected to genetic analysis, as described earlier [44]. Cells were plated at $0.75 \times 10^{6}$ cells per $10-\mathrm{cm}$ dish or $20 \times 10^{4}$ cells per 6 -well plate.

\section{Materials}

FTS was a kind gift from Concordia Pharmaceuticals. Cycloheximide was from Sigma-Aldrich, (St. Louis, MO) and LY294002, U0126, SB203580, and SP600125 were from Calbiochem (San Diego, CA). The antibodies used were: pERK (Sigma-Aldrich); ERK, p-c-jun (Serine 63), c-jun (Santa Cruz Biotechnology, Santa Cruz, CA); pAkt, Akt, p-p38 (Thr180/Tyr182), p38, survivin, and GAPDH (Cell Signaling Technology, Danvers, MA); galectin-1 (PeproTech, Rocky Hill, NJ); galectin-7 (Abcam, Cambridge, MA); pan-Ras (Calbiochem); green fluorescent protein (GFP); naìve goat IgG, horeseradish peroxidase-conjugated goat antimouse IgG or goat anti-rabbit IgG were from Jackson ImmunoResearch Laboratories (West Grove, PA).

The following plasmids were used: PEF1 and PEF1-galectin-7 were the kind gift of Fu-Tong Liu [32]. pEGP-TAM67 (TAM67) [62] was a kind gift from Prof. Lily Vardimon (Department of Biochemistry, Tel Aviv
University). pBabe-Gal7 was generated by amplifying galectin-7 with primers containing the restriction enzymes HindIII (forward) and KpnI (reverse), cloned into PGEM®-T-Easy (Promega), then digested with BamHI/ SalI and cloned into pBabe-Puro digested with BamHI/ SalI.

Protein bands were quantified by densitometry with Image EZQuant-Gel software (EZQuant Ltd., Tel Aviv, Israel).

\section{Ras-GTP assays}

Lysates containing $0.5 \mathrm{mg}$ protein were used to measure Ras-GTP by the glutathione S-transferase fused to the Ras-binding domain of Raf (GST-RBD) pull-down assay as described [63]. The lysates were then westernblotted with pan-Ras Ab, as described above.

\section{RT-PCR analysis}

Extracts of total RNA $(1 \mu \mathrm{g})$ were reversetranscribed in a total volume of $20 \mu \mathrm{l}$ using the Verso ${ }^{\mathrm{TM}}$ RT-PCR Kit (Thermo Scientific, Rockford IL, USA ) according to the manufacturer's instructions. cDNA samples $(1 \mu \mathrm{g})$ were used for RT-PCR (QPCR SYBR ${ }^{\circledR}$ Green Mix Plus ROX Vial; ABgene, [Epsom, UK]).

The primers used were:

GUSB: $\quad$ CTCATTTGGAATTTTGCCGATT

Galectin-1: CCGAGTGAAGATCCCCTTTTTA

CCGAGTGAAGATCCCCTTTTTA

Galectin-7: $\quad$ ATGTCCAACGTCCCCCACAAG

JDP2: CGCCGGGAGAAGAACAAAG GGATTCCCGCTGCAGAAAC

GUSB was used as a reference gene for normalization of relative mRNA expression.

\section{Fluorescence-activated cell sorter analysis}

ST88-14 cells seeded in 6-well plates were treated as described in figure legends, and were then collected and washed with phosphate-buffered saline (PBS). Cells were subjected to Annexin-V-PI kit according to manufacturer's instructions (BD biosciences, Franklin Lakes, NJ USA) and analyzed by fluorescence-activated cell sorter (FACS; FACSCalibur, Becton Dickinson, Los Angeles, CA). Data were analyzed by FlowJo data analysis software package (TreeStar, Ashland, OR).

\section{Transfections}

Plasmid transfection: Transfections with GFPRas(17N), pEGP-TAM67 or GFP (10 cells, $2 \mu \mathrm{g}$ DNA; Ingenio Electroporation, Mirus, Madison, WI) were 
carried out by electroporation using Amaxa ${ }^{\circledR}$ (Lonza, Basel, Switzerland).

Small interfering RNA (siRNA) transfection: ST8814 cells were plated $24 \mathrm{~h}$ prior to transfection $\left(10^{4}\right.$ cells per well in 12-well plates) and transfected with $50 \mathrm{nM}$ ON-TARGETplus JDP2 siRNA oligos as well as ONTARGETplus siCONTROL nontargeting pool, using DharmaFECT 1 Transfection Reagent (Thermo Fisher Scientific) according to the manufacturer's instructions. As an indicator of transfected cells, we used the siGLO Green transfection indicator (Thermo Scientific), followed by treatments as described in the figure legends.

\section{Infections}

Retroviruses were produced by standard protocols, as described [64]. Infected cells were allowed to recover and were selected by puromycin $(1 \mu \mathrm{g} / \mathrm{ml})$. Expression was validated by western blotting and fluorescence microscopy. Cells were maintained in growth medium containing $0.5 \mu \mathrm{g} / \mathrm{ml}$ puromycin, and subjected to routine analysis.

\section{Statistical calculations}

Significant differences between the results obtained by the experimental and the control groups in each experiment were determined by paired or unpaired Student's $t$ test, as appropriate, using Microsoft Excel. P-values that were equal to or smaller than 0.05 were considered significant. Data are presented as means \pm standard error of the mean (SEM). Statistical significance at $p$-values of $* \leq 0.05, * * \leq 0.01$ and $* * * \leq$ 0.001 are indicated.

\section{Image processing}

Adobe Photoshop was employed to adjust for brightness/contrast or cropping of images. The promoter region of galectin-7 was analyzed using Genomatix Genome Analyzer (Genomatix Software GmbH [65]).

\section{ACKNOWLEDGMENTS}

We thank Ms Shirley Smith for editorial assistance.

\section{GRANT SUPPORT}

This work was supported by Grant 2005344 from the United States-Israel Binational Science Foundation (Y. Kloog and A.D. Cox), by the Prajs-Drimmer Institute for The Development of Anti-degenerative Drugs. Y. Kloog Y. Kloog is an incumbent of The Jack H. Skirball Chair in Applied Neurobiology.

\section{REFERENCES}

1. Cox AD,Der CJ. Ras history: The saga continues. Small Gtpases. 2011; 1:2-27.

2. Der CJ,Van Dyke T. Stopping ras in its tracks. Cell. 2007; 129:855-857.

3. Kloog Y,Cox AD. RAS inhibitors: potential for cancer therapeutics. Mol Med Today. 2000; 6:398-402.

4. Cox AD,Der CJ. The dark side of Ras: regulation of apoptosis. Oncogene. 2003; 22:8999-9006.

5. Ahearn IM, Haigis K, Bar-Sagi D,Philips MR. Regulating the regulator: post-translational modification of RAS. Nat Rev Mol Cell Biol. 13:39-51.

6. Cox AD,Der CJ. Ras history: The saga continues. Small Gtpases. 1:2-27.

7. Elad-Sfadia G, Haklai R, Ballan E, Gabius HJ,Kloog Y. Galectin-1 augments Ras activation and diverts Ras signals to Raf-1 at the expense of phosphoinositide 3-kinase. J Biol Chem. 2002; 277:37169-37175.

8. Paz A, Haklai R, Elad-Sfadia G, Ballan E,Kloog Y. Galectin-1 binds oncogenic H-Ras to mediate Ras membrane anchorage and cell transformation. Oncogene. 2001; 20:7486-7493.

9. Elad-Sfadia G, Haklai R, Balan E,Kloog Y. Galectin-3 augments K-Ras activation and triggers a Ras signal that attenuates ERK but not phosphoinositide 3-kinase activity. J Biol Chem. 2004; 279:34922-34930.

10. Barondes SH, Castronovo V, Cooper DN, Cummings RD, Drickamer K, Feizi T, Gitt MA, Hirabayashi J, Hughes C,Kasai K. Galectins: a family of animal beta-galactosidebinding lectins. Cell. 1994; 76:597-598.

11. Yang RY, Rabinovich GA,Liu FT. Galectins: structure, function and therapeutic potential. Expert Rev Mol Med. 2008; 10:e17.

12. Gruson D,Ko G. Galectins testing: new promises for the diagnosis and risk stratification of chronic diseases? Clin Biochem. 45:719-726.

13. Rabinovich GA. Galectin-1 as a potential cancer target. $\mathrm{Br}$ J Cancer. 2005; 92:1188-1192.

14. Lefranc F, Mathieu V,Kiss R. Galectin-1 as an oncotarget in gliomas and melanomas. Oncotarget. 2:892-893.

15. Danguy A, Camby I,Kiss R. Galectins and cancer. Biochim Biophys Acta. 2002; 1572:285-293.

16. Le Mercier M, Lefranc F, Mijatovic T, Debeir O, HaibeKains B, Bontempi G, Decaestecker C, Kiss R,Mathieu $\mathrm{V}$. Evidence of galectin-1 involvement in glioma chemoresistance. Toxicol Appl Pharmacol. 2008; 229:172183.

17. Thijssen VL, Postel R, Brandwijk RJ, Dings RP, Nesmelova I, Satijn S, Verhofstad N, Nakabeppu Y, Baum LG, Bakkers J, Mayo KH, Poirier F, Griffioen AW. Galectin-1 is essential in tumor angiogenesis and is a target for antiangiogenesis therapy. Proc Natl Acad Sci U S A. 2006; 103:15975- 
15980.

18. Salatino M, Croci DO, Bianco GA, Ilarregui JM, Toscano MA,Rabinovich GA. Galectin-1 as a potential therapeutic target in autoimmune disorders and cancer. Expert Opin Biol Ther. 2008; 8:45-57.

19. Rorive S, Belot N, Decaestecker C, Lefranc F, Gordower L, Micik S, Maurage CA, Kaltner H, Ruchoux MM, Danguy A, Gabius HJ, Salmon I, Kiss R,Camby I. Galectin-1 is highly expressed in human gliomas with relevance for modulation of invasion of tumor astrocytes into the brain parenchyma. Glia. 2001; 33:241-255.

20. van den Brule FA, Waltregny D,Castronovo V. Increased expression of galectin-1 in carcinoma-associated stroma predicts poor outcome in prostate carcinoma patients. J Pathol. 2001; 193:80-87.

21. Clausse N, van den Brule F, Waltregny D, Garnier F,Castronovo V. Galectin-1 expression in prostate tumorassociated capillary endothelial cells is increased by prostate carcinoma cells and modulates heterotypic cell-cell adhesion. Angiogenesis. 1999; 3:317-325.

22. Prior IA, Muncke C, Parton RG,Hancock JF. Direct visualization of Ras proteins in spatially distinct cell surface microdomains. J Cell Biol. 2003; 160:165-170.

23. Ashery U, Yizhar O, Rotblat B, Elad-Sfadia G, Barkan B, Haklai R,Kloog Y. Spatiotemporal Organization of Ras Signaling: Rasosomes and the Galectin Switch. Cellular and Molecular Neurobiology. 2006; 26:469-493.

24. Polyak K, Xia Y, Zweier JL, Kinzler KW,Vogelstein B. A model for p53-induced apoptosis. Nature. 1997; 389:300305.

25. Sigal A,Rotter V. Oncogenic mutations of the $\mathrm{p} 53$ tumor suppressor: the demons of the guardian of the genome. Cancer Res. 2000; 60:6788-6793.

26. Puchades M, Nilsson CL, Emmett MR, Aldape KD, Ji Y, Lang FF, Liu TJ,Conrad CA. Proteomic investigation of glioblastoma cell lines treated with wild-type p53 and cytotoxic chemotherapy demonstrates an association between galectin-1 and p53 expression. J Proteome Res. 2007; 6:869-875.

27. Ueda S, Kuwabara I,Liu FT. Suppression of tumor growth by galectin-7 gene transfer. Cancer Res. 2004; 64:56725676.

28. Matsui Y, Ueda S, Watanabe J, Kuwabara I, Ogawa O,Nishiyama H. Sensitizing effect of galectin-7 in urothelial cancer to cisplatin through the accumulation of intracellular reactive oxygen species. Cancer Res. 2007; 67:1212-1220.

29. Celis JE,Olsen E. A qualitative and quantitative protein database approach identifies individual and groups of functionally related proteins that are differentially regulated in simian virus 40 (SV40) transformed human keratinocytes: an overview of the functional changes associated with the transformed phenotype. Electrophoresis. 1994; 15:309-344.

30. Bernerd F, Sarasin A,Magnaldo T. Galectin-7 overexpression is associated with the apoptotic process in UVB-induced sunburn keratinocytes. Proc Natl Acad Sci U S A. 1999; 96:11329-11334.

31. Condaminet B, Redziniak G, Monsigny M,Kieda C. Ultraviolet rays induced expression of lectins on the surface of a squamous carcinoma keratinocyte cell line. Exp Cell Res. 1997; 232:216-224.

32. Kuwabara I, Kuwabara Y, Yang RY, Schuler M, Green DR, Zuraw BL, Hsu DK,Liu FT. Galectin-7 (PIG1) exhibits pro-apoptotic function through JNK activation and mitochondrial cytochrome c release. J Biol Chem. 2002; 277:3487-3497.

33. Villeneuve C, Baricault L, Canelle L, Barboule N, Racca C, Monsarrat B, Magnaldo T,Larminat F. Mitochondrial proteomic approach reveals galectin-7 as a novel BCL-2 binding protein in human cells. Mol Biol Cell. 22:999-1013.

34. Kopitz J, Andre S, von Reitzenstein C, Versluis K, Kaltner H, Pieters RJ, Wasano K, Kuwabara I, Liu FT, Cantz M, Heck AJ,Gabius HJ. Homodimeric galectin-7 (p53induced gene 1) is a negative growth regulator for human neuroblastoma cells. Oncogene. 2003; 22:6277-6288.

35. Demers M, Magnaldo T,St-Pierre Y. A novel function for galectin-7: promoting tumorigenesis by up-regulating MMP-9 gene expression. Cancer Res. 2005; 65:5205-5210.

36. Moisan S, Demers M, Mercier J, Magnaldo T, Potworowski EF,St-Pierre Y. Upregulation of galectin-7 in murine lymphoma cells is associated with progression toward an aggressive phenotype. Leukemia. 2003; 17:751-759.

37. Rorive S, Eddafali B, Fernandez S, Decaestecker C, Andre S, Kaltner H, Kuwabara I, Liu FT, Gabius HJ, Kiss R,Salmon I. Changes in galectin-7 and cytokeratin-19 expression during the progression of malignancy in thyroid tumors: diagnostic and biological implications. Mod Pathol. 2002; 15:1294-1301.

38. Hirota S, Nomura S, Asada H, Ito A, Morii E,Kitamura Y. Possible involvement of c-kit receptor and its ligand in increase of mast cells in neurofibroma tissues. Arch Pathol Lab Med. 1993; 117:996-999.

39. Ferner RE,Gutmann DH. International consensus statement on malignant peripheral nerve sheath tumors in neurofibromatosis. Cancer Res. 2002; 62:1573-1577.

40. Hiatt KK, Ingram DA, Zhang Y, Bollag G,Clapp DW. Neurofibromin GTPase-activating protein-related domains restore normal growth in Nf1-/- cells. J Biol Chem. 2001; 276:7240-7245.

41. McCubrey JA, Steelman LS, Chappell WH, Abrams SL, Montalto G, Cervello M, Nicoletti F, Fagone P, Malaponte G, Mazzarino MC, Candido S, Libra M, Basecke J, Mijatovic S, Maksimovic-Ivanic D, Milella M, Tafuri A, Cocco L, Evangelisti C, Chiarini F,Martelli AM. Mutations and deregulation of Ras/Raf/MEK/ERK and PI3K/ $\mathrm{PTEN} / \mathrm{Akt} / \mathrm{mTOR}$ cascades which alter therapy response. Oncotarget. 3:954-987.

42. Cawthon RM, Weiss R, Xu GF, Viskochil D, Culver M, 
Stevens J, Robertson M, Dunn D, Gesteland R,O'Connell P. A major segment of the neurofibromatosis type 1 gene: cDNA sequence, genomic structure, and point mutations. Cell. 1990; 62:193-201.

43. Ballester R, Marchuk D, Boguski M, Saulino A, Letcher R, Wigler M,Collins F. The NF1 locus encodes a protein functionally related to mammalian GAP and yeast IRA proteins. Cell. 1990; 63:851-859.

44. Barkan B, Starinsky S, Friedman E, Stein R,Kloog Y. The Ras inhibitor farnesylthiosalicylic acid as a potential therapy for neurofibromatosis type 1. Clin Cancer Res. 2006; 12:5533-5542.

45. Barkan B, Kloog Y,Ehrlich M. Phenotypic Reversion of Invasive Neurofibromin-Deficient Schwannoma by FTS: Ras Inhibition Reduces BMP4/Erk/Smad Signaling. Mol Cancer Ther. 2011; 8:1317-1326.

46. Zenz R,Wagner EF. Jun signalling in the epidermis: From developmental defects to psoriasis and skin tumors. Int $\mathrm{J}$ Biochem Cell Biol. 2006; 38:1043-1049.

47. Behrens A, Jochum W, Sibilia M,Wagner EF. Oncogenic transformation by ras and fos is mediated by c-Jun N-terminal phosphorylation. Oncogene. 2000; 19:26572663.

48. Binetruy B, Smeal T,Karin M. Ha-Ras augments c-Jun activity and stimulates phosphorylation of its activation domain. Nature. 1991; 351:122-127.

49. Johnson R, Spiegelman B, Hanahan D,Wisdom R. Cellular transformation and malignancy induced by ras require c-jun. Mol Cell Biol. 1996; 16:4504-4511.

50. Cellurale C, Sabio G, Kennedy NJ, Das M, Barlow M, Sandy P, Jacks T,Davis RJ. Requirement of c-Jun NH(2)terminal kinase for Ras-initiated tumor formation. Mol Cell Biol. 31:1565-1576.

51. Smeal T, Binetruy B, Mercola DA, Birrer M,Karin M. Oncogenic and transcriptional cooperation with Ha-Ras requires phosphorylation of c-Jun on serines 63 and 73 . Nature. 1991; 354:494-496.

52. Eferl R, Ricci R, Kenner L, Zenz R, David JP, Rath M,Wagner EF. Liver tumor development. c-Jun antagonizes the proapoptotic activity of p53. Cell. 2003; 112:181-192.

53. Schreiber M, Kolbus A, Piu F, Szabowski A, MohleSteinlein U, Tian J, Karin M, Angel P,Wagner EF. Control of cell cycle progression by c-Jun is p53 dependent. Genes Dev. 1999; 13:607-619.

54. Broder YC, Katz S,Aronheim A. The ras recruitment system, a novel approach to the study of protein-protein interactions. Curr Biol. 1998; 8:1121-1124.

55. Aronheim A, Zandi E, Hennemann H, Elledge SJ,Karin M. Isolation of an AP-1 repressor by a novel method for detecting protein-protein interactions. Mol Cell Biol. 1997; 17:3094-3102.

56. Pan J, Nakade K, Huang YC, Zhu ZW, Masuzaki S, Hasegawa H, Murata T, Yoshiki A, Yamaguchi N, Lee CH, Yang WC, Tsai EM, Obata Y,Yokoyama KK. Suppression of cell-cycle progression by Jun dimerization protein-2 (JDP2) involves downregulation of cyclin-A2. Oncogene. 29:6245-6256.

57. Heinrich R, Livne E, Ben-Izhak O,Aronheim A. The c-Jun dimerization protein 2 inhibits cell transformation and acts as a tumor suppressor gene. J Biol Chem. 2004; 279:57085715 .

58. Bitton-Worms K, Pikarsky E,Aronheim A. The AP-1 repressor protein, JDP2, potentiates hepatocellular carcinoma in mice. Mol Cancer. 9:54.

59. Hwang HC, Martins CP, Bronkhorst Y, Randel E, Berns A, Fero M,Clurman BE. Identification of oncogenes collaborating with $\mathrm{p} 27 \mathrm{Kip} 1$ loss by insertional mutagenesis and high-throughput insertion site analysis. Proc Natl Acad Sci U S A. 2002; 99:11293-11298.

60. Rasmussen MH, Sorensen AB, Morris DW, Dutra JC, Engelhard EK, Wang CL, Schmidt J,Pedersen FS. Tumor model-specific proviral insertional mutagenesis of the Fos/ Jdp2/Batf locus. Virology. 2005; 337:353-364.

61. Stewart M, Mackay N, Hanlon L, Blyth K, Scobie L, Cameron E,Neil JC. Insertional mutagenesis reveals progression genes and checkpoints in MYC/Runx2 lymphomas. Cancer Res. 2007; 67:5126-5133.

62. Hennigan RF,Stambrook PJ. Dominant negative c-jun inhibits activation of the cyclin D1 and cyclin E kinase complexes. Mol Biol Cell. 2001; 12:2352-2363.

63. Aizman E, Mor A, Levy A, George J,Kloog Y. Ras inhibition by FTS attenuates brain tumor growth in mice by direct antitumor activity and enhanced reactivity of cytotoxic lymphocytes. Oncotarget. 3:144-157.

64. Levy R, Grafi-Cohen M, Kraiem Z,Kloog Y. Galectin-3 promotes chronic activation of K-Ras and differentiation block in malignant thyroid carcinomas. Mol Cancer Ther. 2011; 9:2208-2219.

65. Zang C, Schones DE, Zeng C, Cui K, Zhao K,Peng W. A clustering approach for identification of enriched domains from histone modification ChIP-Seq data. Bioinformatics. 2009; 25:1952-1958.

66. Miller SJ, Rangwala F, Williams J, Ackerman P, Kong S, Jegga AG, Kaiser S, Aronow BJ, Frahm S, Kluwe L, Mautner V, Upadhyaya M, Muir D, Wallace M, Hagen J, Quelle DE, Watson MA, Perry A, Gutmann DH,Ratner N. Large-scale molecular comparison of human schwann cells to malignant peripheral nerve sheath tumor cell lines and tissues. Cancer Res. 2006; 66:2584-2591.

67. Halaschek-Wiener J, Wacheck V, Kloog Y,Jansen B. Ras inhibition leads to transcriptional activation of p53 and down-regulation of Mdm2: two mechanisms that cooperatively increase p53 function in colon cancer cells. Cell Signal. 2004; 16:1319-1327.

68. Hoffman WH, Biade S, Zilfou JT, Chen J,Murphy M. Transcriptional repression of the anti-apoptotic survivin gene by wild type p53. J Biol Chem. 2002; 277:3247-3257.

69. Mirza A, McGuirk M, Hockenberry TN, Wu Q, Ashar H, 
Black S, Wen SF, Wang L, Kirschmeier P, Bishop WR, Nielsen LL, Pickett CB,Liu S. Human survivin is negatively regulated by wild-type p53 and participates in p53dependent apoptotic pathway. Oncogene. 2002; 21 :26132622.

70. Blum R, Jacob-Hirsch J, Rechavi G,Kloog Y. Suppression of survivin expression in glioblastoma cells by the Ras inhibitor farnesylthiosalicylic acid promotes caspasedependent apoptosis. Mol Cancer Ther. 2006; 5:2337-2347.

71. Biran A, Brownstein M, Haklai R,Kloog Y. Downregulation of survivin and aurora a by histone deacetylase and RAS inhibitors: A new drug combination for cancer therapy. Int J Cancer. 2010.

72. Piu F, Aronheim A, Katz S,Karin M. AP-1 repressor protein JDP-2: inhibition of UV-mediated apoptosis through p53 down-regulation. Mol Cell Biol. 2001; 21:3012-3024.

73. Weidenfeld-Baranboim K, Koren L,Aronheim A. Phosphorylation of JDP2 on threonine-148 by the c-Jun $\mathrm{N}$-terminal kinase targets it for proteosomal degradation. Biochem J. 436:661-669.

74. Katz S, Heinrich R,Aronheim A. The AP-1 repressor, JDP2, is a bona fide substrate for the c-Jun N-terminal kinase. FEBS Lett. 2001; 506:196-200.

75. Inagaki Y, Higashi K, Kushida M, Hong YY, Nakao S, Higashiyama R, Moro T, Itoh J, Mikami T, Kimura T, Shiota G, Kuwabara I,Okazaki I. Hepatocyte growth factor suppresses profibrogenic signal transduction via nuclear export of Smad3 with galectin-7. Gastroenterology. 2008; 134:1180-1190.

76. Halaschek-Wiener J, Wacheck V, Schlagbauer-Wadl H, Wolff K, Kloog Y,Jansen B. A novel Ras antagonist regulates both oncogenic Ras and the tumor suppressor p53 in colon cancer cells. Mol Med. 2000; 6:693-704.

77. Thijssen VL, Barkan B, Shoji H, Aries IM, Mathieu V, Deltour L, Hackeng TM, Kiss R, Kloog Y, Poirier F, Griffioen AW. Tumor cells secrete galectin-1 to enhance endothelial cell activity. Cancer Res. 70:6216-6224.

78. Rotblat B, Niv H, Andre S, Kaltner H, Gabius HJ,Kloog Y. Galectin-1(L11A) predicted from a computed galectin-1 farnesyl-binding pocket selectively inhibits Ras-GTP. Cancer Res. 2004; 64:3112-3118. 